\title{
Post hoc analysis of the relationship between baseline white blood cell count and survival outcome in a randomized Phase III trial of decitabine in older patients with newly diagnosed acute myeloid leukemia
}

This article was published in the following Dove Press journal:

Journal of Blood Medicine

8 January 2015

Number of times this article has been viewed

\author{
Christopher Arthur ${ }^{1}$ \\ Jaroslav Cermak ${ }^{2}$ \\ Jacques Delaunay ${ }^{3}$ \\ Jiří Mayer ${ }^{4}$ \\ Grzegorz Mazur ${ }^{5}$ \\ Xavier Thomas ${ }^{6}$ \\ Agnieszka Wierzbowska ${ }^{7}$ \\ Mark M Jones ${ }^{8}$ \\ Erhan Berrak ${ }^{8}$ \\ Hagop Kantarjian 9 \\ 'Department of Haematology, Royal \\ North Shore Hospital, Sydney, NSW, \\ Australia; ${ }^{2}$ Institute of Hematology \\ and Blood Transfusion, Prague, Czech \\ Republic; ${ }^{3}$ Department of Clinical \\ Hematology, University of Nantes, Nantes, \\ France; ${ }^{4}$ Department of Internal Medicine, \\ Masaryk University Hospital Brno, \\ Central European Institute of Technology, \\ Brno, Czech Republic; ${ }^{5}$ Department of \\ Hematology, Wrocław Medical University, \\ Wrocław, Poland; ${ }^{6}$ Department of \\ Hematology, Edouard Herriot Hospital, \\ Lyon, France; ${ }^{7}$ Copernicus Memorial \\ Hospital, Lodz, Poland; ${ }^{8}$ Oncology Product \\ Creation Unit, Eisai Inc., Woodcliff Lake, \\ NJ, USA; 'Department of Leukemia, \\ University of Texas MD Anderson Cancer \\ Center, Houston, TX, USA
}

Correspondence: Christopher Arthur Department of Haematology, Royal North Shore Hospital, Pacific Highway, St Leonards, Sydney, NSW 2065, Australia

Tel +6I 29926760 I

Fax +6I 29906 I635

Email carthur@nsccahs.health.nsw.gov.au
Background: In a Phase III trial, 485 patients ( $\geq 65$ years) with newly diagnosed acute myeloid leukemia received decitabine $20 \mathrm{mg} / \mathrm{m}^{2}$ intravenously for 5 days every 4 weeks or a treatment choice (supportive care or cytarabine $20 \mathrm{mg} / \mathrm{m}^{2}$ subcutaneously for 10 days every 4 weeks).

Materials and methods: We summarized overall and progression-free survival by baseline white blood cell count using two analyses: $<1,1-5,>5 \times 10^{9} / \mathrm{L} ; \leq 10$ or $>10 \times 10^{9} / \mathrm{L}$.

Results: There were 446 deaths (treatment choice, $n=227$; decitabine, $n=219$ ). Median overall survival was 5.0 (treatment choice) versus 7.7 months (decitabine; nominal $P=0.037$ ). Overall survival differences between white blood cell groups were not significant; hazard ratios (HRs) favored decitabine. Significant progression-free survival differences favored decitabine for groups $1-5 \times 10^{9} / \mathrm{L}(P=0.005, \mathrm{HR}=0.67)$, greater than $5 \times 10^{9} / \mathrm{L}(P=0.027, \mathrm{HR}=0.71)$, and up to $10 \times 10^{9} / \mathrm{L}(P=0.003, \mathrm{HR}=0.72)$.

Conclusion: There was a trend toward improved outcome with decitabine, regardless of baseline white blood cell count.

Keywords: decitabine, acute myeloid leukemia, prognosis, leukemia, adult

\section{Introduction}

Each year in the US, approximately 12,330 new cases of acute myeloid leukemia (AML) are reported, and approximately 8,950 patients die from this disease. ${ }^{1}$ Approximately 18,000 new cases of AML are reported annually in the EU. ${ }^{2}$ The incidence of AML is increasing as the population ages, ${ }^{3}$ yet limited treatment options exist for older patients, particularly those with comorbidities. ${ }^{4}$ Recent updates of international treatment guidelines for $\mathrm{AML}^{3,5}$ now include low-intensity cytarabine, 5-azacytidine, and decitabine as therapeutic options.

A hypomethylating agent, decitabine was approved by the European Medicines Agency in 2012 for the treatment of patients $\geq 65$ years of age with newly diagnosed de novo and secondary AML. ${ }^{6}$ It is approved by the US Food and Drug Administration for use in patients with previously treated and untreated de novo and secondary myelodysplastic syndrome of all French-American-British subtypes and intermediate-1, intermediate-2, and high-risk groups as categorized using the International Prognostic Scoring System. ${ }^{7}$ In previous Phase II studies, decitabine $20 \mathrm{mg} / \mathrm{m}^{2}$ administered as a 1-hour intravenous infusion either daily for 5 consecutive 
days every 4 weeks ${ }^{8}$ or on days $1-10$ every 4 weeks ${ }^{9}$ demonstrated activity in older patients (aged $\geq 60$ years) with AML and poor- or intermediate-risk cytogenetics. ${ }^{8,9}$

In a large Phase III trial $(n=485)$, patients aged 65 years or older with newly diagnosed AML received a 1-hour intravenous infusion of decitabine $20 \mathrm{mg} / \mathrm{m}^{2}$ for 5 consecutive days every 4 weeks or a treatment choice, with physician's advice, of either supportive care or cytarabine $20 \mathrm{mg} / \mathrm{m}^{2} \mathrm{sub}$ cutaneous injection for 10 consecutive days every 4 weeks. ${ }^{10}$ Enrolled patients were required to have a white blood cell (WBC) count below $40 \times 10^{9} / \mathrm{L}$, although because of protocol deviations, some patients who had WBC counts greater than $40 \times 10^{9} / \mathrm{L}$ were enrolled. Decitabine-treatment benefit (as measured by overall survival [OS]) was more evident in patients with high baseline bone marrow blasts $(>30 \%)$ and across all WBC counts. ${ }^{10}$ If low-dose hypomethylating agents induce an antileukemic action through differentiation, it would be expected that the more proliferative AML would respond poorly; however, responses favoring decitabine across all WBC counts in this study suggested that proliferation rates were not a determining factor in decitabine response. This post hoc analysis was undertaken to assess the relationship between baseline WBC count and survival outcomes in this study.

\section{Materials and methods}

OS and progression-free survival (PFS) were summarized by baseline WBC count subgroups (first analysis, $<1$, $1-5$, and $>5 \times 10^{9} / \mathrm{L}$; second analysis, $\leq 10 \times 10^{9} / \mathrm{L}$ or $\left.>10 \times 10^{9} / \mathrm{L}\right)$, ie, WBC counts at start of therapy. Statistical comparisons were made using log-rank tests and hazard ratios (HRs), along with two-sided 95\% confidence intervals from a Cox regression model; HRs less than 1 indicated an advantage for decitabine. Both the log-rank test and Cox regression were stratified (as was done for the primary analyses of the study data) by age ( $<70$ years, $\geq 70$ years), cytogenetic risk (intermediate, poor), and Eastern Cooperative Oncology Group (ECOG) performance status $(0-1,2)$. Median survival and PFS were estimated from unadjusted Kaplan-Meier product-limit estimates. ${ }^{11}$

\section{Results \\ Patients}

A total of 485 patients aged 65 years or older with newly diagnosed AML were randomized to treatment with either decitabine $(n=242)$ or treatment choice $(n=243$ [cytarabine, $\mathrm{n}=215$; supportive care, $\mathrm{n}=28]$ ). At baseline, the median age of patients in each of the treatment groups was 73 years. ${ }^{10}$
In the decitabine and treatment-choice groups, respectively, $64 \%$ and $65 \%$ of patients had de novo AML, time since AML diagnosis was 14 days (range 3-346) and 15 days (range 0-398), and 63\% and 64\% had intermediate-risk disease. Median WBC count was $3.10 \times 10^{9} / \mathrm{L}$ (range $0.3-127.0$ ) in the decitabine group and $3.69 \times 10^{9} / \mathrm{L}$ (range $0.5-80.9$ ) in the treatment-choice group, and $44 \%$ and $42 \%$ of patients, respectively, had more than $50 \%$ bone marrow blasts. The primary analysis for this study was based on a clinical cutoff date in 2009, at which time 396 deaths had occurred. For this post hoc analysis of the intent-to-treat population, a mature data set using a 2010 clinical cutoff was used; at that time, 446 deaths had occurred (treatment choice, $\mathrm{n}=227$; decitabine, $\mathrm{n}=219)$. ${ }^{10}$

\section{Survival outcomes}

The primary efficacy analysis (in October 2009) showed a nonsignificant trend toward an OS benefit with decitabine (median 7.7 versus 5.0 months for treatment choice). At the 2010 clinical cutoff, the median (95\% confidence interval) OS was 5.0 months (4.3-6.3) for patients in the treatmentchoice group and 7.7 months (6.2-9.2) for those in the decitabine group $(\mathrm{HR}=0.82,95 \%$ confidence interval $0.68-0.99$; nominal $P=0.037) .{ }^{10}$

\section{Relationship between survival and baseline WBC counts}

Overall, median baseline WBC counts were relatively low in this patient population (Table 1), which was expected, as the exclusion criteria required patients to have WBC counts less than $40 \times 10^{9} / \mathrm{L}^{10}$ For each of the baseline WBC-count subgroups of less than $1,1-5$, and greater than $5 \times 10^{9} / \mathrm{L}$, differences in OS for the treatment-choice group compared with the decitabine group were not significant, but HRs favored decitabine in each of these WBC-count subgroups. A significant difference in PFS in favor of decitabine was observed in patients with baseline WBC counts of $1-5 \times 10^{9} / \mathrm{L}(P=0.005)$ and $>5 \times 10^{9} / \mathrm{L}(P=0.028)$. All HRs again favored decitabine for each of these WBC-count subgroups (Table 1). ${ }^{11}$

Regarding the baseline WBC-count subgroup of up to $10 \times 10^{9} / \mathrm{L}$ or greater than $10 \times 10^{9} / \mathrm{L}$, no significant difference was found between treatment groups in OS for either subgroup (Table 1). A significant difference $(P=0.003)$ in PFS in favor of decitabine was found between treatment groups for patients with a baseline WBC count of up to $10 \times 10^{9} / \mathrm{L}$.

Findings for OS and PFS by treatment group for patients with baseline WBC up to $10 \times 10^{9} / \mathrm{L}$ and greater than $10 \times 10^{9} / \mathrm{L}$ are given in Kaplan-Meier curves (Figure 1). 
Table I Relationship between survival outcomes for patients receiving decitabine or treatment choice and baseline white blood cell count for patients with baseline white blood cell counts

\begin{tabular}{|c|c|c|c|c|}
\hline Outcome & $\begin{array}{l}\text { White blood cell } \\
\text { count } \times 10^{9} / \mathrm{L}\end{array}$ & $\begin{array}{l}\text { Median for treatment } \\
\text { choice, }{ }^{\mathrm{a}, \mathrm{b}} \text { months } \mathrm{n} / \mathbf{N}\end{array}$ & $\begin{array}{l}\text { Median for decitabine, } \\
\text { months event } n / N\end{array}$ & $\begin{array}{l}\text { Nominal P-value } \\
\text { HR }(95 \%, \mathrm{Cl})^{\mathrm{d}}\end{array}$ \\
\hline \multirow[t]{12}{*}{ Overall survival } & All patients & 5.0 & 7.7 & $P=0.037$ \\
\hline & & $227 / 243$ & $219 / 242$ & $H R=0.82(0.68,0.99)$ \\
\hline & $<1$ & 4.9 & 8.6 & $P=0.640$ \\
\hline & & $20 / 22$ & $22 / 25$ & $\mathrm{HR}=0.85(0.42,1.70)$ \\
\hline & $\mathrm{I}-5$ & 5.9 & 9.5 & $P=0.079$ \\
\hline & & $106 / 115$ & $104 / 119$ & $\mathrm{HR}=0.78(0.58,1.03)$ \\
\hline & $>5$ & 4.3 & 6.3 & $P=0.180$ \\
\hline & & $94 / 99$ & $88 / 93$ & $H R=0.82(0.60,1.10)$ \\
\hline & $\leq 10$ & 5.7 & 8.6 & $P=0.083$ \\
\hline & & $161 / 180$ & $160 / 181$ & $\mathrm{HR}=0.82(0.66,1.03)$ \\
\hline & $>10$ & 4.0 & 6.5 & $P=0.101$ \\
\hline & & $53 / 56$ & $54 / 56$ & $\mathrm{HR}=0.7 \mathrm{I}(0.47,1.07)$ \\
\hline \multirow[t]{12}{*}{ Progression-free survival } & All patients & 2.1 & 3.7 & $P=0.002$ \\
\hline & & $235 / 243$ & $229 / 242$ & $H R=0.74(0.6 \mathrm{I}, 0.89)$ \\
\hline & $<1$ & 2.2 & 5.5 & $P=0.914$ \\
\hline & & $20 / 22$ & $24 / 25$ & $\mathrm{HR}=0.96(0.48,1.93)$ \\
\hline & $1-5$ & 2.9 & 3.8 & $P=0.005$ \\
\hline & & $110 / 115$ & $111 / 119$ & $H R=0.67(0.5 \mathrm{I}, 0.89)$ \\
\hline & $>5$ & 2.1 & 3.4 & $P=0.028$ \\
\hline & & $98 / 99$ & $89 / 93$ & $H R=0.7 I(0.53,0.97)$ \\
\hline & $\leq 10$ & 2.2 & 3.8 & $P=0.003$ \\
\hline & & $173 / 180$ & $169 / 181$ & $H R=0.72(0.57,0.90)$ \\
\hline & $>10$ & 2.1 & 3.5 & $P=0.215$ \\
\hline & & $55 / 56$ & $55 / 56$ & $H R=0.76(0.50,1.17)$ \\
\hline
\end{tabular}

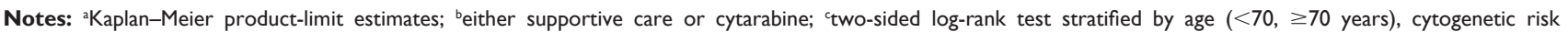
(intermediate, poor), and ECOG PS $(0-1,2)$; ${ }^{\circ}$ Cox regression model stratified by age $(<70, \geq 70$ years), cytogenetic risk (intermediate, poor), and ECOG PS (0-I, 2). HR $<\mathrm{I}$ indicates advantage for decitabine.

Abbreviations: $\mathrm{Cl}$, confidence interval; ECOG PS, Eastern Cooperative Oncology Group performance score; HR, hazard ratio.

For patients with baseline WBC counts up to $10 \times 10^{9} / \mathrm{L}$, no significant difference in median OS was found between the decitabine and treatment-choice groups. Similarly, no significant difference in median OS was observed between groups for patients with WBC counts greater than $10 \times 10^{9} / \mathrm{L}$ (Figure 1A).

No significant difference in median PFS between the decitabine and treatment choice groups was seen for patients with baseline WBC counts higher than $10 \times 10^{9} / \mathrm{L}$ (Figure 1B). However, a significant difference between the groups was found for patients with baseline WBC counts of up to $10 \times 10^{9} / \mathrm{L}(P=0.003){ }^{11}$

\section{Discussion}

This post hoc analysis of data from a large Phase III trial of patients aged 65 years or older with newly diagnosed AML found that the OS and PFS data were consistent with the overall results of the trial. ${ }^{10} \mathrm{HRs}$ indicated a trend toward improved survival outcome with decitabine, regardless of baseline WBC count, in this older patient population. Significant differences between treatment groups for
PFS were found in several baseline WBC-count subgroups $\left(1-5,>5\right.$, and $\left.\leq 10 \times 10^{9} / \mathrm{L}\right)$. The lack of significance for an OS or PFS benefit in the groups with baseline WBC counts lower than $1 \times 10^{9} / \mathrm{L}$ may have been related to the smaller number of patients (treatment choice, $n=22$; decitabine, $n=25$ ) in these groups. In addition, it was noted that WBC counts were lower than expected in the AML population, perhaps due to the advanced age of the study group.

In a recent retrospective study in older patients ( $>60$ years) with AML, a peripheral blast count of $\geq 0.1 \times 10^{9} / \mathrm{L}$ (indicative of more proliferative disease) was reported to be predictive of a poorer outcome with best supportive care or nonintensive chemotherapy compared with intensive chemotherapy, whereas patients with less proliferative disease $\left(<0.1 \times 10^{9} / \mathrm{L}\right)$ had similar outcomes to best supportive care and intensive chemotherapy. ${ }^{12}$ Similarly, a previous Phase II study of the same decitabine regimen used in our analysis in patients aged 60 years or older with AML and poor- or intermediate-risk cytogenetics demonstrated that complete responses were highest in patients with the lowest presenting peripheral 


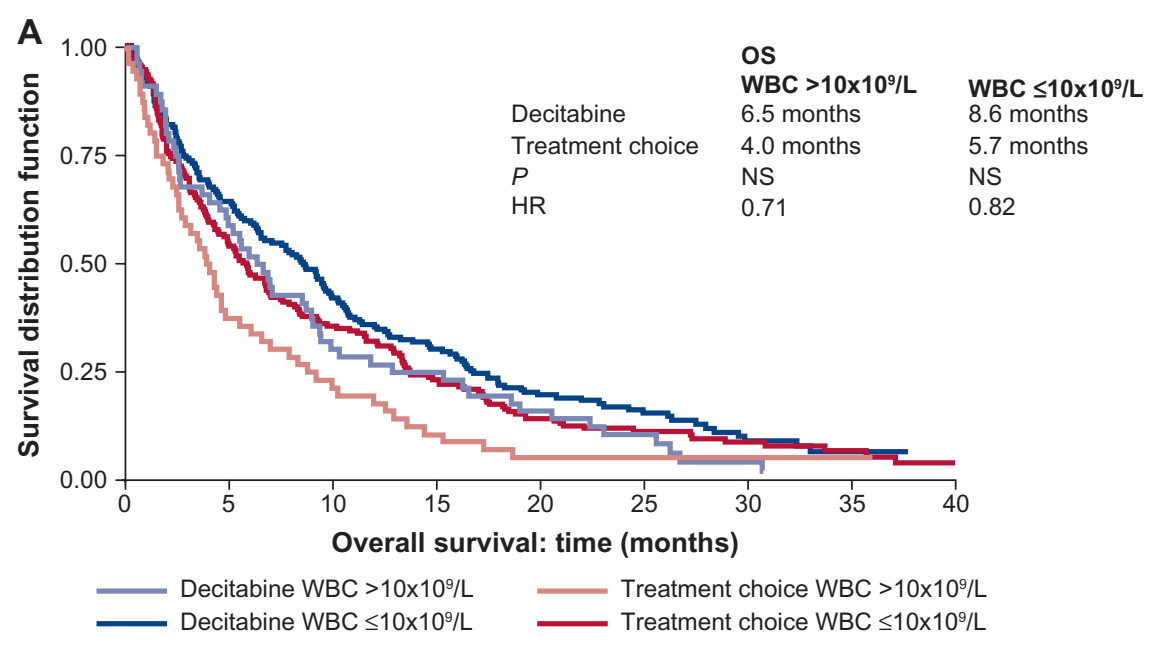

\begin{tabular}{|l|c|c|c|c|c|c|c|c|}
\hline \multicolumn{2}{|l|}{ Number at risk at each time point, WBC $>10 \times 10^{9} / \mathrm{L}$} \\
\hline Months & 0 & 5 & 10 & 15 & 20 & 25 & 30 & 35 \\
\hline Decitabine & 56 & 33 & 17 & 14 & 9 & 5 & 2 & 0 \\
\hline $\begin{array}{l}\text { Treatment } \\
\text { choice }\end{array}$ & 56 & 21 & 12 & 6 & 3 & 3 & 1 & 1 \\
\hline
\end{tabular}

\begin{tabular}{|l|c|c|c|c|c|c|c|c|c|}
\hline Number at risk at each time point, WBC $\leq 10 \times 10^{9} / \mathrm{L}$ \\
\hline Months & 0 & 5 & 10 & 15 & 20 & 25 & 30 & 35 & 40 \\
\hline Decitabine & 181 & 115 & 75 & 54 & 33 & 20 & 9 & 2 & 0 \\
\hline $\begin{array}{l}\text { Treatment } \\
\text { choice }\end{array}$ & 180 & 96 & 63 & 41 & 25 & 16 & 9 & 5 & 3 \\
\hline
\end{tabular}

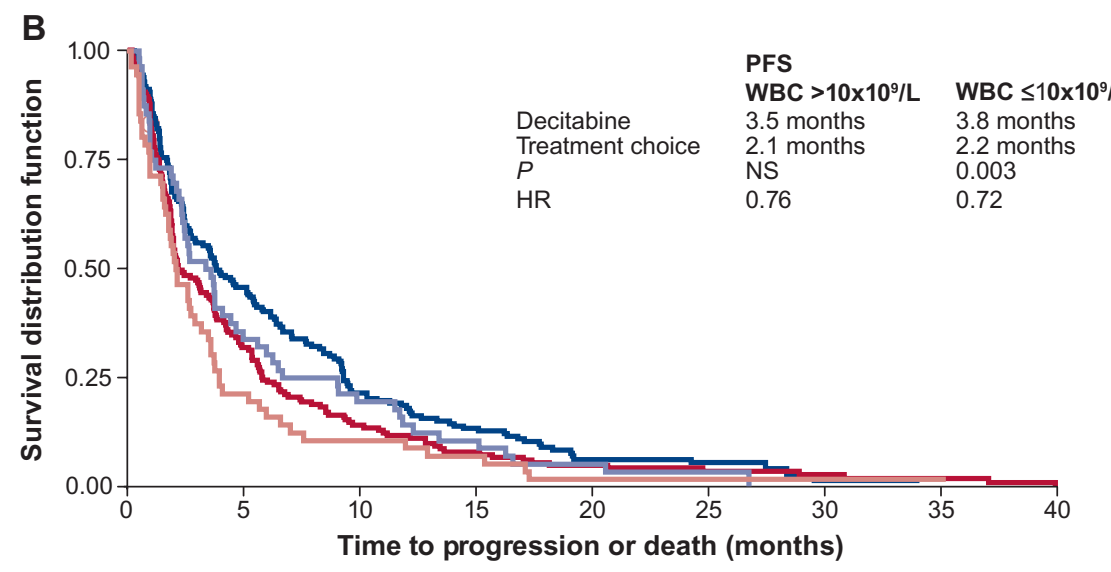

\begin{tabular}{|c|c|c|c|c|c|c|c|c|c|}
\hline & & $\begin{array}{l}\text { Dec } \\
\text { Dec }\end{array}$ & $\begin{array}{l}\text { WB } \\
\text { WB }\end{array}$ & $\begin{array}{l}\times 10^{9} \\
\times 10^{9}\end{array}$ & - & $\begin{array}{l}\text { Treatr } \\
\text { Treatr }\end{array}$ & $\begin{array}{l}\text { hoice } \\
\text { hoice }\end{array}$ & $\begin{array}{l}>10 \\
\leq 10\end{array}$ & \\
\hline Number at $r$ & each & oint, & $>10 x$ & & & & & & \\
\hline Months & 0 & 5 & 10 & 15 & 20 & 25 & 30 & 35 & \\
\hline Decitabine & 56 & 19 & 11 & 6 & 3 & 1 & 0 & 0 & \\
\hline $\begin{array}{l}\text { Treatment } \\
\text { choice }\end{array}$ & 56 & 12 & 6 & 4 & 1 & 1 & 1 & 1 & \\
\hline Number at $r$ & each & oint, & $\leq 10 x$ & & & & & & \\
\hline Months & 0 & 5 & 10 & 15 & 20 & 25 & 30 & 35 & 40 \\
\hline Decitabine & 181 & 81 & 37 & 23 & 9 & 7 & 1 & 0 & 0 \\
\hline $\begin{array}{l}\text { Treatment } \\
\text { choice }\end{array}$ & 180 & 56 & 23 & 13 & 8 & 5 & 3 & 2 & 1 \\
\hline
\end{tabular}

Figure I Overall survival (A) and progression-free survival (B) by treatment group for patients with baseline white blood cell count greater than $10 \times 10^{9} / \mathrm{L}$ and up to $10 \times 10^{9} / \mathrm{L}$.

Abbreviations: HR, hazard ratio; NS, not significant; OS, overall survival; PFS, progression-free survival; WBC, white blood cell. 
blood absolute blast counts $(29 \%$ for patients with blast counts $\left.<1 \times 10^{9} / \mathrm{L}\right)$. No complete responses occurred in patients with blast counts higher than $10 \times 10^{9} / \mathrm{L}$ (indicative of more proliferative disease) ${ }^{8}$ In comparison, the current analysis found responses to decitabine across all patient subgroups, using baseline WBC count as a measure of the degree of proliferative disease. Moreover, in the original study from which this subanalysis was conducted, decitabine responses were more evident in patients with high baseline bone marrow blasts $(>30 \%)$ and across all WBC counts. ${ }^{10}$ These disparate findings may reflect the different methods used to measure the degree of proliferative disease (WBC count or peripheral blood absolute blast count) in older patients with AML. In addition, it is possible that response to decitabine may be determined by a combination of factors, including the level of WBCs, the number of nonmobilized bone marrow blasts, and the extent of blast infiltration into the peripheral blood.

These results may be limited by the fact that this was a post hoc analysis and because patient numbers in some WBC-count subgroups were small. In addition, OS data may have been confounded because patients might have received further treatment after study completion.

Nevertheless, these findings suggest that older patients with newly diagnosed AML may respond to decitabine therapy, regardless of their baseline WBC counts. Additional studies may further elucidate any relationship between baseline WBC levels and outcomes in this patient population.

\section{Acknowledgments}

These data were presented in part at the Annual Meeting of the American Society of Clinical Oncology, June 1-5, 2012, in Chicago, IL (abstract 6559). Clinicaltrials.gov identifier: NCT00260832. The original study and this analysis were funded by Eisai Inc. The authors thank Yvonne E Yarker, $\mathrm{PhD}, \mathrm{CMPP}$ of Peloton Advantage for medical writing and editorial support, funded by Eisai Inc., and Yuhan Li, MS of Eisai Inc. for statistical analyses.

\section{Disclosure}

JD has acted as a consultant for Novartis and Genzyme. JM has acted as a consultant for and received research funding

Journal of Blood Medicine

\section{Publish your work in this journal}

The Journal of Blood Medicine is an international, peer-reviewed, open access, online journal publishing laboratory, experimental and clinical aspects of all topics pertaining to blood based medicine including but not limited to: Transfusion Medicine; Blood collection, Donor issues, Transmittable diseases, and Blood banking logistics; Immunohematology; Artificial and alternative from Eisai, is a member of Eisai's board of directors and serves on advisory committees for Eisai Inc. MMJ and EB are employees of Eisai. HK has received research funding from Eisai. The other authors report no conflicts of interest in this work.

\section{References}

1. Jemal A, Siegel R, Xu J, Ward E. Cancer statistics, 2010. CA Cancer J Clin. 2010;60:277-300.

2. Rodriguez-Abreu D, Bordoni A, Zucca E. Epidemiology of hematological malignancies. Ann Oncol. 2007;18 Suppl 1:i3-i8.

3. National Comprehensive Cancer Network. NCCN Clinical Practice Guidelines in Oncology: Acute Myeloid Leukemia. Version 2.2012. Fort Washington (PA): NCCN; 2012. Available from: http://www. nccn.org/professionals/physician_gls/pdf/aml.pdf. Accessed January 10, 2013.

4. Fey MF, Dreyling M. Acute myeloblastic leukaemias and myelodysplastic syndromes in adult patients: ESMO Clinical Practice Guidelines for diagnosis, treatment and follow-up. Ann Oncol. 2010;21 Suppl 5: v158-v161.

5. Dohner H, Estey EH, Amadori S, et al. Diagnosis and management of acute myeloid leukemia in adults: recommendations from an international expert panel, on behalf of the European LeukemiaNet. Blood. 2010;115:453-474.

6. European Medicines Agency. Dacogen (decitabine) [summary of product characteristics]. 2014. Available from: http://www.ema.europa. eu/ema/index.jsp?curl=pages/medicines/human/medicines/002221/ human_med_001589.jsp\&mid=WC0b01ac058001d124. Accessed July 31, 2013.

7. Eisai. Dacogen [package insert]. Woodcliff Lake (NJ): Eisai; 2010.

8. Cashen AF, Schiller GJ, O'Donnell MR, Dipersio JF. Multicenter, phase II study of decitabine for the first-line treatment of older patients with acute myeloid leukemia. J Clin Oncol. 2010;28:556-561.

9. Blum W, Garzon R, Klisovic RB, et al. Clinical response and miR-29b predictive significance in older AML patients treated with a 10-day schedule of decitabine. Proc Natl Acad Sci U S A. 2010;107:7473-7478.

10. Kantarjian HM, Thomas XG, Dmoszynska A, et al. Multicenter, randomized, open-label, phase III trial of decitabine versus patient choice, with physician advice, of either supportive care or low-dose cytarabine for the treatment of older patients with newly diagnosed acute myeloid leukemia. J Clin Oncol. 2012;30:2670-2677.

11. Arthur C, Cermak J, Delaunay J, et al. Post hoc analysis of relationship between baseline white blood cell count and survival outcome in a randomized phase III trial of decitabine in older patients with newly diagnosed acute myeloid leukemia [abstract]. Poster presented at: Annual Meeting of the American Society of Clinical Oncology; Chicago, IL; June 1-5, 2012.

12. Murray DJ, Muddana J, Borg A, Harrison BD. Acute myeloid leukemia: low peripheral blast count may predict better outcome with best supportive care than with intensive chemotherapy in older patients [abstract]. Blood. 2012;112:3550.

\section{Dovepress}

blood based therapeutics; Hematology; Biotechnology/nanotechnology of blood related medicine; Legal aspects of blood medicine; Historical perspectives. The manuscript management system is completely online and includes a very quick and fair peer-review system. Visit http://www.dovepress.com/ testimonials.php to read real quotes from published authors. 